\title{
Prosthetic-restorative approach for the restoration of a severely eroded dentition
}

\section{Abordagem protética-restauradora para uma dentição com erosão severa}

DIEGO P. BRILHANTE ${ }^{1}$

SILVIA M. FRASCA

DANIELA M. BOTEGA

\section{RESUMO}

Objetivo: Apresentar uma reabilitação adesiva tipo boca total em caso de severa erosão dental, com grande número de dentes afetados, perda de DVO, estética e anatomia.

Relato do caso: Um tratamento com coroas e facetas em cerâmica pura foi proposto a um paciente do sexo masculino de 32 anos de idade apresentando desgaste dentário clinicamente significativo em todos os dentes, com exposição da dentina e redução na altura clínica da coroa. Foi proposta uma abordagem de tratamento contemplando coroas e facetas de cerâmica pura. As restaurações indiretas em cerâmica pura se mostram duráveis, estéticas e protegem a estrutura dentária, restabelecendo a dimensão vertical de oclusão de forma muito satisfatória.

Conclusão: Restaurações indiretas, com base na nova dimensão vertical da oclusão (DVO), podem restabelecer a anatomia e a função em casos de erosão severa.

Palavras-chave: Cerâmica. Erosão dentária. Reabilitação bucal.

\begin{abstract}
Objective: To present a full-mouth adhesive rehabilitation in the severely eroded dentition with a large number of affected teeth, loss of VDO, esthetics, and anatomy.

Case report: A 32-year-old male patient presented with clinically significant dental wear affecting all teeth, with dentin exposure and short clinical crowns. A treatment approach with all-ceramic crowns and veneers was proposed. All-ceramic indirect restorations proved durable, aesthetic, and protected the tooth structure, restoring the vertical dimension of occlusion to a very satisfactory degree.

Conclusion: Indirect restorations based on the new vertical dimension of occlusion (VDO) can restore anatomy and function in cases of severely eroded dentition.
\end{abstract}

Key-words: Ceramics. Tooth erosion. Mouth rehabilitation.

1 Private practice; Instructor, Specialty Training Programs in Prosthodontics and Oral Rehabilitation, Sobracid; Instructor, Specialty Training Program in Prosthodontics, ABO-RS, Porto Alegre, RS, Brazil.

2 Private practice; Instructor, Specialty Training Program in Implant Dentistry, ABO-RS, Porto Alegre, RS, Brazil.

3 Associate Professor, Universidade Federal do Rio Grande do Sul School of Dentistry, Porto Alegre, RS, Brazil. 


\section{INTRODUCTION}

Erosion-related dental wear is becoming an increasingly common presenting complaint in private-practice dentistry, as well, as an increasingly important issue when considering the longevity and health of the dentition. Erosion can be defined as the loss of tooth structure due to a chemical process of multifactorial origin that does not involve bacterial action. ${ }^{1,2,3,4,5}$

Awake and sleep bruxism, unbalanced dietary habits (with high intake of acidic foods and beverages, such as carbonated beverages, fruit, fruit juices, vinegar), and abnormal production of intrinsic acid in disorders, such as bulimia nervosa, acid regurgitation, and hiatal hernia are all causal factors of dental wear. Insufficient salivary flow rate, the buffering capacity and composition of saliva, use of medications, and aging are other etiological cofactors. ${ }^{1,6}$

The diagnosis of erosive wear is based on clinical appearance, as there is no device available for detection. Aspects such as smooth, polished, intact enamel along the gingival margin, significant loss of tooth structure, and a flat occlusal/incisal surface, with loss of anatomy and a significant proportion of exposed dentin, are typical signs. ${ }^{1}$

Although the chief complaint is usually aesthetic, loss of vertical dimension of occlusion (VDO) and functional impairment can be observed. Conventional therapy for such cases consists of full-coverage crowns, which entails removal of the remaining dental structure, tooth devitalization, and, in more severe cases, post-and-core buildup. With the increased effectiveness of adhesive cementation, allceramic crowns and veneers can be used to address these cases with minimal or no dental preparation, thus providing a minimally invasive technique, provided that correct diagnosis and planning are done. . $^{4,8,9,10}$ The advantages of ceramic as compared to composite-resin restorations are better color stability, wear resistance, and esthetics. ${ }^{5,11}$

Proper treatment improves oral hygiene, reduces thermal sensitivity and susceptibility to carious lesions, prevents pulp involvement, prevents additional wear, and restores esthetics and function, thus improving quality of life. ${ }^{2}$ The treatment plan consists of a clinical, functional, and esthetic evaluation to establish an etiology-based treatment strategy. This is followed by the preventive and restorative phases, ending with an adequate maintenance program. ${ }^{2}$ The three-step technique for fullmouth rehabilitation, using ceramic restorations and adhesive cementation, was developed to simplify the dentist's task, as the diagnostic wax-up is performed progressively through interactions between the patient, dentist, and technician. This minimally invasive technique takes into account three essential parameters: VDO, position of the incisal edge, and position of the occlusal plane. ${ }^{12,13,14,15}$

Taking into account several investigations, the following conclusion can be made: under acidic conditions, all restorative materials show degradation over time (surface roughness, decrease in surface hardness, loss of substance). However, it appears that ceramic and composite materials show good durability. ${ }^{1}$ Within this context, this article reports a case of conservative prosthetic rehabilitation in a patient with generalized dental wear.

\section{CASE REPORT}

A 32-year-old male patient presented with significant erosive dental wear, with dentin exposure and reduced facial height secondary to reduced VDO, as seen in Figure 1.

A minimally invasive treatment approach with all-ceramic indirect restorations was proposed. The patient had stable periodontal condition, good oral hygiene and general health, no known drug allergies, and was a nonsmoker. 


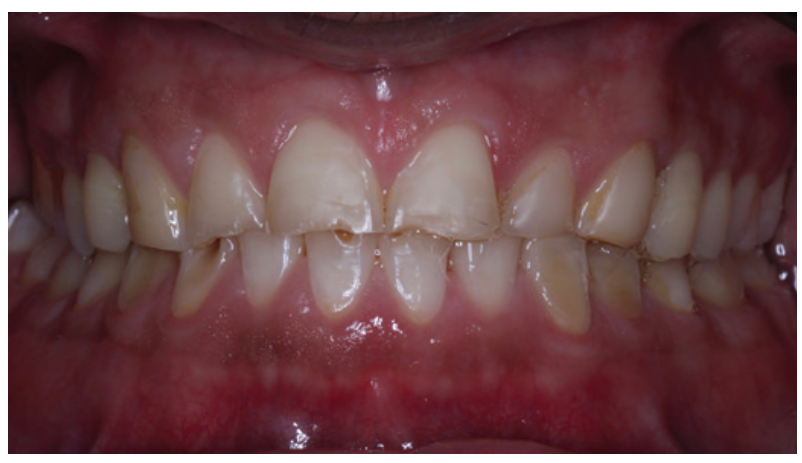

Figure 1. Patient with significant dental wear caused by erosion.

After clinical and radiographic examination, impressions of the maxillary and mandibular arches were obtained using addition silicone. These were then used to obtain type IV die stone casts. Photographs of the face (front and lateral views) were obtained at rest and with the patient smiling to assist in the planning and diagnostic wax-up phases. The maxillary cast was mounted onto a semi-adjustable articulator with the aid of a facebow.

In the basis of clinical assessment using a jig made from self-curing acrylic resin the mandibular cast was mounted onto the articulator with a $3 \mathrm{~mm}$ increase in VDO. An esthetic guide was fabricated from light-curing resin by applying and curing the resin directly onto one of the patient's central incisors, without acid etching or application of adhesive, to simulate the optimal volume and length of the central incisor. This guide was transferred onto the model and served as the initial reference for wax-up of the anterior teeth.

The articulator-mounted casts, esthetic guide of the central incisor, and clinical photographs were sent to the dental laboratory for diagnostic wax-ups of the anterior teeth and fabrication of a silicone index or key of these areas. Using the silicone index, a mock-up of the maxillary and mandibular anterior teeth was made intraorally with bis-acrylic resin.

Due to the complexity of the case, a waxup of the anterior segment was used as a guide for treatment. This enabled evaluation of esthetic and phonetic outcomes, and gave the patient the opportunity to experience and express his opinion on the course of treatment, as anxiety and insecurity regarding the profound changes in the teeth and face that will occur are very common in such cases. The necessary corrections detected at this stage by the dentist and patient were reported to the laboratory technician, who applied this new information to adapt and fabricate the maxillary and mandibular posterior wax-ups accordingly.

Using a new silicone guide, now of the entire maxillary and mandibular arches (except for the second molars), a new mock-up was made on the patient's teeth. This mock-up was worn for seven days, allowing evaluation by the patient and his family.

While keeping the posterior mock-up intraoral to stabilize the occlusion and preserve the new VDO, the anterior teeth were prepared using silicone guides. Due to the massive tissue loss caused by the erosive process, preparation was limited to the removal of sharp edges and adjustment of the placement axis of the future ceramic restorations.

To obtain impressions, the double-cord mechanical gingival retraction technique was used. Then, addition silicone was applied using the simultaneous impression technique. Once the impression had been removed and found suitable, the mock-up was redone and the impression sent to the laboratory.

Veneers were fabricated from lithium disilicate porcelain, Figure 2.

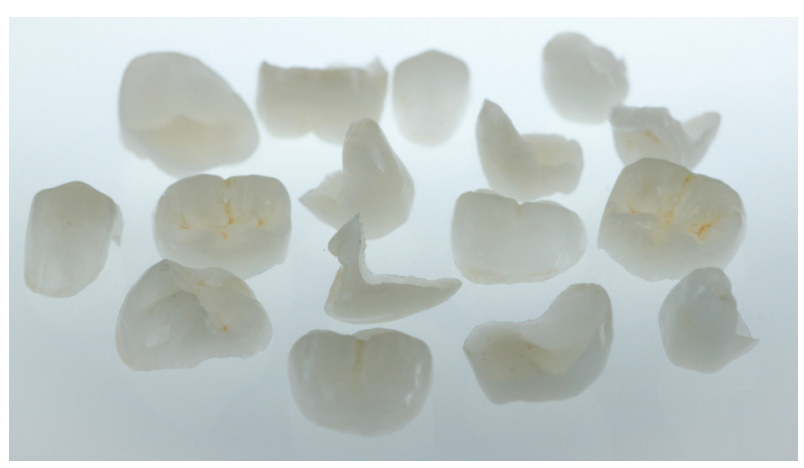

Figure 2. Veneers made from IPS e.max Press MT lithium disilicate glass ceramic. 
The restorations were evaluated individually in the patient's mouth, in relation to their fit to the corresponding tooth remnant, contact points, masticatory function, phonetics, and harmony. A Try-in Paste was used to find the optimal shade of resin cement, as the reduced thickness of these restorations means the color of the cement can interfere with the final outcome. Once the best shade had been selected, the try-in cement was removed with water.

The ceramic restorations were etched with $10 \%$ hydrofluoric acid for 20 seconds. Subsequently, they were rinsed and dried, and the silane bonding agent was applied and left to dry. The underlying tooth structure was conditioned with $37 \%$ phosphoric acid for 15 seconds and rinsed copiously under cottonroll isolation. Then, Single Bond Universal Adhesive was applied to the dentin and enamel surfaced and to the inner aspects of the ceramic restorations. Excess adhesive was removed with vigorous bursts of air, and light-curing was not performed.

A resin cement, shade A1, was applied to the veneers, which were then placed individually onto the corresponding teeth. Excess cement was removed and light-curing was performed. The same clinical sequence and ceramic materials used in the anterior segment were also used in the posterior segment.

With all restorations in position, articulating film was used to evaluate and adjust the occlusal contact points in maximum intercuspation and during jaw protrusion and lateral excursion. Minor occlusal adjustment was required at some points, Figure 3.

As the maintenance program included overnight use of a full-coverage splint, an alginate impression of both arches and the articulator-mounted casts were used to fabricate a Michigan splint to be worn by the patient during sleep.

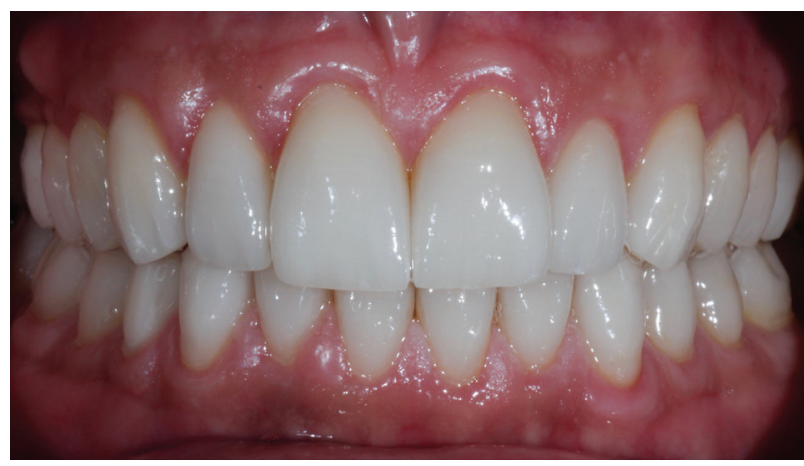

Figure 3. Patient at completion of the adhesive rehabilitation.

\section{Discussion}

Dental wear can result from erosive, attritional (bruxism), or abrasive processes, or from a combination thereof. Erosion is the progressive loss of mineralized tooth structures (enamel and, subsequently, dentin) due to the frequent presence of acidic agents. It is typically defined by wedge-shaped depressions, often in vestibular and cervical areas. ${ }^{8}$ The dental consequences of abrasion and erosion are manifold: loss of enamel with progressive exposure of large dentin surfaces, loss of tooth anatomy, shortening of teeth and adaptive mandibular displacement with impact on function and aesthetics, discoloration of exposed dentin surfaces, tooth sensitivity, pulp complications, increased risk of carious lesions, loss of marginal fit of existing restorations, and fracture of restorations. ${ }^{6}$

Erosion may be extrinsic or intrinsic in origin. Extrinsic causes include carbonated beverages and acidic fruit juices. The main intrinsic factor is gastric acid. In addition, behavioral factors, including eating and drinking habits, regular exercise to dehydration, reduced salivary flow, excessive oral hygiene, and an unhealthy lifestyle (chronic alcoholism) are predisposing factors for dental erosion. ${ }^{1}$

Adhesive techniques are providing less invasive and more conservative treatment 
options for erosive tooth wear, especially in young patients. Management of dental tissue loss ranges from prevention to full-mouth rehabilitation, depending on the severity of the case. Before starting treatment, it is important that the cause of erosion be determined and stopped. The case reported herein provides an example of late intervention on the effects of dental erosion. The patient had a history of carbonated beverage intake, which poses a high risk of development of dental erosion. ${ }^{8}$

All-ceramic restorations have advanced to the point where they are aesthetic, highly resistant, and biocompatible with both hard and soft tissues. The recent development of vitreous ceramics has made all-ceramic restorations stronger and more durable when in occlusion than previous ceramics. The demand for metal-free dentures has increased because of marketing practices, but also because patients want dental crowns that provide the look of natural teeth, with similar optical properties. IPS e.max, for instance, is a lithium disilicate material that provides translucency, durability, and strength. Maximal dental preservation and excellent esthetics can be achieved with a combination of silicate-based ceramics and adhesive cementation.

In the case reported herein, full-mouth adhesive rehabilitation was performed with an increase in VDO, as there was evidence of loss of dental tissue in the anterior and posterior teeth. Preparation was minimal, and the integrity of all enamel margins was maintained; thus, the dental structure was protected and the pulp was not compromised. The obvious drawbacks of metal-ceramic crowns are the highly invasive approach required and the more dramatic failure patterns observed. Rehabilitation with conventional crowns requires that teeth be reduced 1 to $1.5 \mathrm{~mm}$, which carries a risk of compromising pulp integrity; thus, it should be avoided, especially in young patients. ${ }^{7,11}$ The use of more conservative restorative approaches, such as partial direct and indirect restorations, provides an undeniable advantage and has a promising impact on the treatment of severe erosion. The use of resin cements is another advantage, given their high acid resistance and high bond strength. ${ }^{6,8}$

In the present case, the three-step fullmouth rehabilitation technique, first reported by Vailati and Belser ${ }^{12-14}$ and subsequently reproduced in several studies was used. ${ }^{2-4,15}$ Three laboratory steps alternate with three clinical steps, allowing the technician and dentist to interact constantly during planning and execution of treatment. During the first laboratory step, instead of a full-mouth waxup, the technician waxes up only the vestibular aspect of the maxillary teeth.

Subsequently, the dentist uses an intraoral mock-up test to evaluate esthetics and check the occlusal plane. During the second laboratory step, attention is given to the posterior quadrants, creating an occlusal wax-up, and determining the new VDC; then, the dentist performs the second clinical step of obtaining a stable occlusion in the new OVD by means of provisional composite restorations in the four posterior quadrants, using silicone indexes made on the wax-up. Finally, the third laboratory step consists of reconstructing the palatal aspect of the anterior teeth, restoring the anterior guidance, and restoring the vestibular aspect with bonded veneers. The main advantage is minimal tooth preparation. In addition, the use of provisional restorations made from mockups facilitates management by the dentist, who can work either on only one quadrant or on two antagonist quadrants per session. ${ }^{10}$ Thus, considering what was approached, this case was concluded showing how indirect prostheses can restore function and aesthetics in a case of severe dental erosion. 


\section{REFERENCES}

1. Lussi A., Hellwig E., Ganss C., Jaeggi T. Buonocore Memorial Lecture. Dental Erosion. Oper Dent 2009, 34: 251-62. https://www.ncbi. nlm.nih.gov/pubmed/19544813

2. Gargari M., Ceruso FM, Prete V., Pujia A. Prosthetic-restorativeapproachfortherestoration of tooth wear. VDO increase, rehabilitation of anatomy and function and aesthetic restoration of anterior teeth. Case report. Oral Implantol (Rome) 2012; 5: 70-4. https://www.ncbi.nlm.nih. gov/pubmed/23285409

3. Vailati F., Vaglio G., Belser UC. Full-mouth minimally invasive adhesive rehabilitation to treat severe dental erosion: a case report. J Adhes Dent 2012; 14: 83-92. https://www.ncbi. nlm.nih.gov/pubmed/21734973

4. Grutter L., Vailati F. Full-mouth adhesive rehabilitation in case of severe dental erosion, a minimally invasive approach following the 3-step technique. Eur J Esthet Dent 2013; 8: 358-75. https://www.ncbi.nlm.nih.gov/ pubmed/23957037

5. Moretto G., Pupo YM, Bueno ALN, Araujo FO. Prosthetic Rehabilitation of a Patient With Gastroesophageal Reflux Disease: Five-Year Follow-up. Oper Dent 2016; 41: 132-7. https:// www.ncbi.nlm.nih.gov/pubmed/26449592

6. Dietschi D., Argente A. A Comprehensive and Conservative Approach for the Restoration of Abrasion and Erosion. Part I: Concepts and Clinical Rationale for Early Intervention Using Adhesive Techniques. Eur J Esthet Dent 2011; 6: 20-33. https://www.ncbi.nlm.nih.gov/ pubmed/21403925

7. Mizrahi B. Combining traditional and adhesive dentistry to reconstruct the excessively worn dentition. Eur J Esthet Dent 2008; 3: 270-89. https://www.ncbi.nlm.nih.gov/ pubmed/19655543

8. Al-Salehi SK. Restorative management of intrinsic and extrinsic dental erosion. J Indian
Prosthodont Soc 2014; 14: s215-21. https:// www.ncbi.nlm.nih.gov/pubmed/26199519

9. Nam J., Tokutomi H. Using zirconia-based prosthesis in a complete-mouth reconstruction treatment for worn dentition with the altered vertical dimension of occlusion. J Prosthet Dent 2015; 113: 81-5. https://www.ncbi.nlm.nih. gov/pubmed/25438749

10. Schlichting LH, Resende TH, Reis KR, Magne $P$. Simplified treatment of severe dental erosion with ultrathin CAD-CAM composite occlusal veneers and anterior bilaminar veneers. $\mathbf{J}$ Prosthet Dent 2016; 116: 474-82. https://www. ncbi.nlm.nih.gov/pubmed/27132785

11. Groten M. Complete esthetic and functional rehabilitation with adhesively luted all-ceramic restorations- Case report over 4.5 years. Quintessence Int 2007; 38: 723-31. https:// www.ncbi.nlm.nih.gov/pubmed/17873979

12. Vailati F., Belser UC. Full-mouth adhesive rehabilitation of a severely eroded dentition: the three-step technique. Part 1. Eur J Esthet Dent 2008a, 3: 30-44. https://www.ncbi.nlm.nih.gov/ pubmed/19655557

13. Vailati F., Belser UC. Full-mouth adhesive rehabilitation of a severely eroded dentition: the three-step technique. Part 2. Eur J Esthet Dent 2008b, 3: 128-46. https://www.ncbi.nlm.nih.gov/ pubmed/19655527

14. Vailati F., Belser UC. Full-mouth adhesive rehabilitation of a severely eroded dentition: the three-step technique. Part 3. Eur J Esthet Dent 2008c, 3: 236-57. https://www.ncbi.nlm.nih.gov/ pubmed/19655541

15. Vailati F., Carciofo S. Treatment planning of adhesive additive rehabilitations: the progressive wax-up of the three-step technique. Int J Esthet Dent 2016; 11: 356-77. https://www.ncbi.nlm.nih.gov/ pubmed/27433550

Submetido em: 8-1-2019

Aceito em: 26-12-2019 